\title{
ESTUDOS CONSTRUTIVISTAS DE MERCADO E LÓGICAS INSTITUCIONAIS: PROPOSIÇÃO DE UM QUADRO ANALIITICO PARA UMA ORGANIZACÇÃO DO MERCADO BRASILEIRO DE ALIMENTOS ORGÂNICOS
}

\author{
CONSTRUCTIVIST MAKET STUDIES AND INSTITUTIONAL LOGICS: \\ PROPOSAL OF AN ANALYTICAL FRAMEWORK FOR AN \\ ORGANIZATION OF THE BRAZILIAN ORGANIC FOOD MARKET
}

\section{Daniel de Oliveira Barata Merabet}

Doutorando em Administração pela Universidade do Grande Rio (Rio de Janeiro/Brasil).

E-mail: danielmerabet@hotmail.com 


\section{RESUMO}

Historicamente mercado é retratado em marketing como uma entidade neutra, concreta e objetiva. Contudo, essa concepção foi questionada com a consolidação dos estudos construtivistas de mercado que apontam para a observação das práticas e a forma como constituem agenciamentos sociotécnicos. Ainda assim, este último conceito é tido como nebuloso em termos operacionais de pesquisa, sobretudo com relação à dimensão política dos mercados. A fim de superar o desafio identificado, este ensaio possui o intento de estabelecer um diálogo com a perspectiva das lógicas institucionais segundo a qual os interesses dos atores são socialmente construídos em um campo organizacional entendido como uma arena de disputa política. Decorre desse diálogo uma proposta analítica para realização de investigação científica no âmbito do mercado brasileiro de produtos orgânicos. A escolha desse campo pode ser justificada por dois motivos: a) a pluralidade de atores e de interesses presente no desenvolvimento do marco regulatório confere aderência à agenda de pesquisa dos estudos construtivistas de mercado que contesta a representação típica do fenômeno em marketing baseada na economia neoclássica; e b) em sua estrutura de governança, está prevista a atuação das Comissões da Produção Orgânica, organização composta por diferentes atores governamentais e da sociedade civil que acena para a existência de diferentes lógicas institucionais materializadas em diferentes práticas de mercado. Neste contexto, pelo menos duas lógicas institucionais podem estar relacionadas com as práticas de mercado revelando a importância da dimensão política para pesquisas futuras no âmbito dos estudos construtivistas de mercado.

Palavras-chave: Estudos Construtivistas de Mercado. Lógicas Institucionais. Sociologia Econômica. Mercado de Alimentos Orgânicos.

\section{ABSTRACT}

The market has historically been portrayed in marketing as a neutral, concrete and objective entity. However, this conception has been questioned with the consolidation of constructivist market studies that indicate the observation of practices and how they constitute socio-technical agencements. Nonetheless, the latter concept is considered unclear in operational research terms, particularly in relation to the political dimension of markets. With the aim of tackling the challenge identified, this study endeavours to establish a dialogue with the institutional logics perspective, according to which the actors interests are socially constructed in an organizational field, understood as an arena of political dispute. An analytical proposal stems from this dialogue for the conduct of a scientific investigation within the Brazilian organic product market. The selection of this field can be justified for two reasons: a) the plurality of actors and interests present in the development of a regulatory framework confers adherence to the constructivist market studies research agenda, which contests the typical representation of the phenomenon in marketing, based on neoclassical economics, and b) the Organic Production Committees`activities are included in its governance structure; the organization is made up of various government actors and civil society, which indicates the existence of different institutional logics, which are materialized in distinct market practices. In this context, at least two institutional logics may be related to market practices, revealing the importance of the political dimension for future research within the domain of constructivist market studies.

Keywords: Constructivist Market Studies. Institutional Logics. Economic Sociology. Brazilian Organic Food Market. 


\section{INTRODUÇÃO}

De forma hegemônica, mercado em marketing é retratado a partir dos pressupostos da escola neoclássica de economia. Neste sentido, mercado é tido como entidade neutra, concreta e objetiva, constituído por atores racionais e regulado por mecanismos de preços. Essa concepção recentemente foi colocada à prova com a consolidação dos estudos construtivistas de mercado, cujo intento, entre outros, era o de promover novas possibilidades de teorizações sobre mercado em marketing (KJELLBERG; HELGESSON, 2007a; ARAUJO, 2007; ARAUJO et al., 2008; ARAUJO; FINCH; KJELLBERG, 2010; MASON et al., 2015).

A obra de Callon (1998), localizada no âmbito da sociologia econômica, possui uma grande influência sobre os estudos construtivistas de mercado naárea de marketing. Além de compreender que os fenômenos econômicos estão incrustrados no tecido social, tal obra aproxima os desenvolvimentos teóricos da teoria ator-rede (LATOUR, 2012) para proceder a investigações científicas sobre o mercado. Soma-se a essa tradição teórica, o desenvolvimento da concepção de práticas de mercado (KJELLBERG; HELGESSON, 2006; 2007a) que, ao invés de verificar tão somente o funcionamento das práticas comerciais de atores econômicos, conforme previsto pela escola de pensamento dominante em marketing (SHAW; JONES, 2005), aponta para a existência de outras práticas realizadas também por atores governamentais e da sociedade civil que, direta ou indiretamente, contribuem para a formação de um dado mercado (GEIGER et al., 2014).

No âmbito dos estudos construtivistas de mercado, uma das formas de observar as práticas de mercado seria com a utilização em conjunto com conceito de agenciamento sociotécnico (HAGBERG, 2016; GEIGER; FINCH, 2016; HOPKINSON, 2017). Trata-se de um agregado composto por atores humanos e não humanos que possui a capacidade de agir como um só e de diversas formas dependendo da sua configuração (CALLON, 2005; 2007; 2013; ÇALISKAN; CALLON, 2010). Contudo, este conceito é tido como nebuloso em termos operacionais de pesquisa dificultando a apreensão da dimensão política dos mercados (BEUZA; FERRARO, 2018). De fato, esta dimensão política é reconhecidamente controversa no enquadramento teórico proposto por Callon (BUTLER, 2010; CALLON, 2010; COCHOY; GIRAUDEAU; MCFALL, 2010; PELLANDINI-SIMÁNYI, 2016). A fim de superar o desafio identificado com a utilização do conceito de agenciamento, este ensaio possui o intento de estabelecer um diálogo entre duas tradições teóricas para propor um quadro analítico para uma organização do mercado brasileiro de alimentos orgânicos: os estudos construtivistas de mercado e a perspectiva das lógicas institucionais.

No âmbito da análise institucional, a vertente das lógicas institucionais emerge como uma alternativa em meio aos debates que circundam a vertente neoinstitucional (MEYER; ROWAN, 1977; DIMAGGIO; 
POWELL, 2005) que, em decorrência do seu caráter conservador, determinista e apolítico, acabaria por projetar sombras sobre a capacidade de agência dos indivíduos (CARVALHO; VIEIRA; GOULART, 2005; MACHADO-DA-SILVA; FONSECA; CRUBELLATE, 2005; HUDSON et al., 2015; YU, 2015). Embora as lógicas institucionais exerçam influência sobre indivíduos e organizações, isso não significa que esses atores não possuam espaço para agir, uma vez que práticas materiais e simbólicas mobilizadas pelos atores sociais podem desenvolver mecanismos para conformar ou desafiar padrões estabelecidos (FRIEDLAND; ALFORD, 1991; VENKATARAMAN, 2016). Portanto, dada a existência de múltiplas lógicas institucionais e observado que os interesses dos atores são socialmente construídos em um campo organizacional entendido como uma arena de disputa de política (MACHADO-DA-SILVA; FILHO; ROSSONI, 2010; SCHNEIBERG; LOUNSBURY, 2017), tem-se nessa perspectiva uma possibilidade mais direta para acessar as regras e recursos que estão em jogo em relação ao conceito de agenciamento sociotécnico.

Em termos metodológicos, recorre-se ao formato de ensaio teórico orientado pelo seguinte questionamento: como a perspectiva de lógicas institucionais pode contribuir para a apreensão da dimensão política dos mercados em pesquisas baseadas no conceito de práticas de mercado? O objetivo reside em investigar as bases onto-epistemológicas das duas perspectivas teóricas e oferecer uma a proposta analítica de investigação científica no âmbito do mercado brasileiro de produtos orgânicos. Dessa forma, o ensaio adotará o formato de adaptação teórica já que estabelecerá pontes entre duas correntes teóricas distintas (JAAKKOLA, 2020) para apresentar um novo enquadramento, com proposições e orientações de análise (GILSON; GOLDBERG, 2015). Em termos operacionais (JAAKKOLA, 2020), o ponto de partida (domínio teórico) será baseado nos estudos construtivistas de mercado, especificamente, no conceito de práticas de mercado, enquanto que a perspectiva das lógicas institucionais será utilizada como recurso para preencher as lacunas identificadas, como a dimensão política dos mercados.

Embora o ensaio teórico não demande comprovação empírica para confirmação dos pressupostos que apresenta (MENEGHETTI, 2011; GILSON; GOLDBERG, 2015), optou-se por contextualizar a discussão no âmbito do mercado brasileiro de alimentos orgânicos por dois motivos: a) a existência de interesses não somente econômicos, mas sociais e políticos presentes no desenvolvimento do marco regulatório (SANTOS; HIGGINS, 2016; SAMBUICHI, 2017) confere aderência à agenda de pesquisa dos estudos construtivistas de mercado que contestam a representação típica do fenômeno em marketing baseada na economia neoclássica (ARAUJO, 2007), centrada na relação diádica entre consumidores e empresas; e b) em sua estrutura de governança, apresenta uma organização que se adequa à proposta de investigação, a Comissão da Produção Orgânica (CPOrg), composta por diferentes atores governamentais e da sociedade civil, o que suscita a existência de diferentes lógicas institucionais (THORNTON; OCASIO; LOUNSBURY, 2015) materializadas em diferentes práticas de mercado (KJELLBERG; HELGESSON, 2006; 2007a). 
O campo será baseado em dados secundários majoritariamente provenientes de legislação específica considerando leis, decretos, portarias e instruções normativas publicadas no período de 2003 a 2015, além de informações publicadas por órgãos governamentais.

Este ensaio está dividido da seguinte forma, além da introdução: a primeira seção apresentará as origens e fundamentos teóricos do movimento dos estudos construtivistas de mercado em marketing; em seguida será apresentada a perspectiva das lógicas institucionais e a forma com que pode contribuir para o avanço do referido movimento; a terceira seção apresenta brevemente as características do mercado brasileiro de produtos orgânicos, bem como a Comissão da Produção Orgânica, destacando sua relevância para a proposta de quadro analítico para investigações futuras; por fim, serão apresentadas as considerações finais, bem como desafios da proposta analítica apresentada.

\section{OS ESTUDOS CONSTRUTIVISTAS DE MERCADO EM MARKETING: ORIGENS E FUNDAMENTOS TEÓRICOS}

Existem à disposição diversas abordagens na literatura acadêmica para investigar não somente os fenômenos decorrentes do funcionamento dos mercados, mas sua própria natureza constitutiva (RUIZ, 2012; GEIGER; KJELLBERG; SPENCER, 2012). Especificamente na área de marketing, os estudos sobre formação de mercados decorrem em parte de um movimento que ganhou força nos meados da década de 2000 e que encarava com insatisfação a forma com que mercado era retratado na disciplina (KJELLBERG; HELGESSON, 2007a; ARAUJO, 2007; ARAUJO et al., 2008; ARAUJO; FINCH; KJELLBERG, 2010).

Historicamente, mercado é retratado em marketing como uma entidade concreta e objetiva (VENKATESH; PEÑALOZA, 2006; VAREY, 2010). Tal condição pode ser explicada uma vez compreendida a proximidade da escola de pensamento gerencial com a escola neoclássica de economia, cuja hegemonia foi estabelecida ao longo das décadas de 1950 e 1960 e que deslocou para a margem outras formas de pensamento de marketing já existentes (SHETH; GARDNER; GARRETT, 1988; SHAW; JONES, 2005).

Segundo essa abordagem, mercado pode ser visto como mecanismo reconciliador de diferentes interesses existentes entre produtores e consumidores. A teoria da escolha racional, importante pressuposto da economia neoclássica, foi desenvolvida para explicar decisões que maximizam o lucro para a firma e utilidade para o consumidor individual. Dessa forma, mercado compreende vários tomadores de preço anônimos municiados com perfeita informação para efetuarem decisões eficientes. A competição pelos melhores resultados decorrentes das transações econômicas regulará, de forma impessoal, o comportamento dos preços, sendo o equilíbrio de interesses entre produtores e compradores, a melhor situação de alocação de recursos para ambos. Trata-se, por fim, de um mecanismo natural sobre o qual 
pouca intervenção estatal deverá ocorrer para viabilizar a situação de livre comércio (ARENDT, 1983; VAREY, 2010; REDMOND, 2018).

Esta conceptualização de mercado foi contestada ainda no final na década de 1980. Por exemplo, Arndt $(1979 ; 1981$; 1983) propôs uma perspectiva institucional baseada na economia política para analisar sistemas de marketing. A adoção da perspectiva institucional tornaria possivel realizar investigações tanto no âmbito do micro, principal foco da escola gerencial de marketing, quanto no macro, tendo como unidade de análise a negociação de objetivos comuns e conflitantes entre as coalizões políticas internas da organização e os interesses dos grupos externos (ARNDT, 1983). Ainda assim, o arcabouço teórico propugnado pela escola neoclássica de economia continuou a marcar de forma contundente a maneira com que mercado é retratado em marketing (SHAW; JONES, 2005).

A insatisfação por parte de pesquisadores da área com a forma hegemônica com que mercado era (e ainda é) conceptualizado em marketing fomentou a emergência dos chamados estudos construtivistas de mercado, movimento que encontrou inicialmente inspiração na obra Laws of the Markets de Michel Callon, publicada em 1998 (ARAUJO et al., 2008; ARAUJO; KJELLBERG, 2009). A obra que, inicialmente poderia ser posicionada no que se convencionou chamar de nova sociologia econômica (SWEDBERG, 2004; SMELSER; SWEDBERG, 2005), possui diretas influências da Teoria Ator-Rede (TAR) (LATOUR, 2012) e dos Estudos de Ciência e Tecnologia (LATOUR, 2000).

De forma geral, pode-se dizer que a nova sociologia econômica possui pelo menos duas vertentes: a sociologia econômica norte-americana, que possui expoentes como Neil Fligstein e Mark Granovetter, e a sociologia econômica francesa, podendo ser representeada por Pierre Bourdieu, Michel Callon e Luc Boltanski. Enquanto a corrente norte-americana segue os desenvolvimentos marcados pelas noções de enraizamento da atividade econômica no tecido social, pela análise de redes e pelo entendimento da economia como fenômeno socialmente construído, a corrente francesa parece privilegiar aspectos mais estruturais e defende a importância dos interesses que cercam as relações sociais (SWEDBERG, 2004). Já Fligstein e Douter (2012) apresentam três escolas de pensamento que integram o que os autores chamam de sociologia dos mercados: a) a baseada em redes (GRANOVETTER, 1985); b) em instituições (FLIGSTEIN, 2001; 2007) e; c) na tese da performatividade (CALLON, 1998). Comum às escolas e às vertentes está o fato de o mercado ser retratado como arena social formada por uma pluralidade de atores, o interesse em explicar os fenômenos da troca, da competição e da produção e a forma com que aspectos sociais, políticos, históricos e intervenções governamentais contribuem para construção dos mercados.

Com relação à influência dos pressupostos da teoria ator-rede sobre os estudos de mercado destaca-se o reconhecimento do mesmo estatuto ontológico entre atores humanos e não-humanos (CALLON, 1998). Neste sentido, o arranjo social heterogêneo (uma vez formado por atores humanos e 
não-humanos) explicaria a ação econômica de agentes imersos em relações de cálculo cuja dinâmica incorreria na produção da realidade dos mercados (SWEDBERG, 2004; FLIGSTEIN; DOUTER, 2012). Um actant, ator humano ou não humano, capaz de fazer a diferença, provocar transformações ou modificar uma situação, exerce uma ação que deixa rastros visíveis, caso contrário não constitui ação. Tem-se com o princípio da simetria, uma forma mais plural de reconhecer agência em virtude das associações mútuas entre humanos, com suas práticas discursivas, políticas e estratégicas, e elementos não humanos, como textos, conhecimento científico, instrumentos de política pública, objetos, artefatos técnicos, repercutindo sobre a configuração da rede (COORE, 2004; SAYES, 2013; ANDRADE; VALADÃO, 2017). Não existe ator sem rede nem rede sem atores, o que permite inferir que também não faz sentido falar em relações produzidas fora da rede (LATOUR, 1999; 2012).

A natureza interdisciplinar dos estudos construtivistas de mercado permite a inclusão de diversos atores nos processos de investigação científica, incluindo não somente produtores e consumidores, mas agentes de políticas públicas e de organizações não governamentais, e objetos e dispositivos de mercado. Trata-se de uma abordagem que reconhece tanto da dimensão material quanto social dos mercados ao mesmo tempo em que evita os posicionamentos extremos situados em cada um desses polos (GEIGER, KJELLBERG, SPENCER, 2012).

Dentre as principais premissas do movimento destacam-se que: a) mercados são produzidos por práticas; b) o conhecimento de marketing é performativo; c) as trocas de marketing demandam enquadramento; e d) agentes de marketing são coletivos híbridos (ARAÚJO; FINCH; KJELLBERG, 2010a; MASON et al., 2015). Isso implica em ver na disciplina potencial para gerar teorizações sobre mercado não observando somente práticas de marketing dos gerentes de empresas e as trocas econômicas entre empresas e consumidores, como apregoados pela escola gerencial, mas práticas de diversos atores e a forma como convivem em determinado espaço.

Vale ressaltar ainda que esta nova corrente de pesquisa em marketing já abriga uma expressiva quantidade de trabalhos conceituais e empíricos (KJELLBERG; HELGESSON, 2006; 2007; HAGBERG; KJELLBERG; 2010; FINCH; GEIGER, 2011; NILSSON; HELGESSON, 2015; FUENTES; FUENTES, 2017; KJELLBERG; OLSON, 2017;), além de chamadas específicas em importantes periódicos como Marketing Theory (ARAUJO, KJELLBERG; SPENCER, 2008) Journal of Marketing Management (MASON, KJELLBERG e HAGBERG, 2015) e Consumption Markets \& Culture (COCHOY; TROMPETTE; ARAUJO, 2016) algo que ajuda a consolidar os contornos do movimento.

Um ponto importante que merece menção no desenvolvimento histórico do movimento reside na importante contribuição dos trabalhos de Kjellberg e Helgesson (2006; 2007a). Com o objetivo de refletir sobre como teorias influenciam as práticas que constituem mercado, os autores propõem um framework 
para realização de pesquisas empíricas. A partir de uma posição onto-epistemológica denominada de construtivismo prático, revelando uma clara intenção de dissociação do construtivismo social que concede primazia à ação humana no processo de construção da realidade, os autores apresentam três premissas: a) o foco deve recair sobre as práticas de mercado e não somente sobre práticas de marketing; b) a prática deve ser entendida como um conceito de nível micro; e c) toda descoberta referente à prática de mercado é temporal e deve ser investigada em interação com outras para produzir efeitos sobre o mercado. Por prática de mercado entende-se todas as atividades que constituem mercado (KJELLBERG; HELGESSON, 2006, p. 842).

As práticas de mercado são performativas e podem ser caracterizadas de três formas: de troca, representacionais e normativas (KJELLBERG; HELGESSON, 2006; 2007a). As práticas de troca são aquelas atividades que envolvem a troca econômica de bens e serviços. Já as práticas representacionais são aquelas que representam trocas econômicas em mercados, ou seja, relacionadas à forma com que mercado e seu funcionamento são descritos. Por fim, as trocas normativas são as atividades que contribuem para estabelecer orientações sobre que forma assumirá um mercado de acordo com interesse de determinado ator ou grupo.

Essas práticas mantêm vínculo entre si e, embora permitam descrições, devem ser entendidas como importante recurso analítico para investigar as dinâmicas de formação de mercados. Para tanto, o conceito de translação (LATOUR, 1986; 2012) também contribui como recurso epistemológico, indicando o deslocamento de interesses (CAMILLIS; ANTONELLO, 2016; TONELLI, 2016) podendo atores apresentar comportamento de intermediários, quando transportam significados sem adulterá-los, e de mediadores, quando promove alterações no significado ou nos elementos que asseguram seu deslocamento (LATOUR, 2012).

O processo contínuo de translação dos atores forma o que é conhecido como cadeias de translação, agregados sociomateriais que estabilizam ou desestabilizam uma realidade social (LATOUR, 1986; 2012). É no momento em que ocorre a translação por um actant que é possível identificar e investigar o fenômeno da performatividade e da produção de múltiplas versões de mercado (KJELLBERG; HELGESSON, 2006). Mais ainda, se a perspectiva da teoria ator-rede pretende explicar como um agregado sociomaterial, um agenciamento, exerce ação de forma unitária, abre-se espaço para investigar por que certas versões de mercado prevalecem enquanto que outras são deslocadas para a margem ou completamente silenciadas (HELGESSON; KJELLBERG, 2005).

Enquanto as práticas de mercado encerram uma unidade de análise de nível micro (KJELLBERG; HELGESSON, 2006; 2007a), um agenciamento sociotécnico combina elementos heterogêneos ajustados uns aos outros, propiciando a análise em nível macro. Trata-se de um agregado que possui a capacidade 
de agir como um só e de diversas formas dependendo da sua configuração (CALLON, 2005; 2007). Como a translação explica a ação na teoria ator-rede, ela se torna unidade básica de construção dos agenciamentos (CALLON, 2009a) ao mesmo tempo em que revela a materialidade das práticas de mercado (KJELLBERG; HELGESSON, 2006; 2007a).

Recentemente, correntes de pesquisa dentro do movimento dos estudos construtivistas de mercado consideram que a permanente construção desse fenômeno decorre justamente do entendimento da dinâmica dos múltiplos agenciamentos sociomateriais de mercado e respectivos enquadramentos (ÇALISKAN; CALLON, 2010; CALLON, 2010b). Como o agenciamento é formado pelas práticas sociais que o constitui, um agenciamento sociotécnico de mercado abrangeria: a) a produção, circulação e a troca de bens; b) regras, convenções, dispositivos técnicos, sistemas de metrologia, infraestrutura logística, textos, discursos, narrativas, conhecimento técnico e científico além de habilidades e competências dos indivíduos; c) delimitação de um espaço de confrontação entre diferentes atores (ÇALISKAN; CALLON, 2010, p. 3). A preferência por agenciamento ao invés de rede se deve ao intento de ressaltar que o agregado sociomaterial age e pode fazer atores agirem além de destacar o foco para a forma com que diferentes agenciamentos de mercado disputam por hegemonia. Isto implica em uma espécie de competição entre diferentes versões de mercado (KJELLBERG; HELGESSON, 2006; 2007a).

Mesmo diante de todos os pressupostos teóricos que sustentam o movimento na área de marketing, alguns desafios ainda precisam ser superados. Existem debates direcionados à teoria ator-rede sobre sua suposta neutralidade (LAW; HASSARD, 1999; ALCADINAPI; TURETA, 2009; ALCADIPANI; HASSARD, 2010; TONELLI, 2016), algo que limitaria a apreensão da dimensão política dos mercados e privilegiaria a dimensão econômica mesmo nos estudos sobre formação de mercado (PELLANDINI-SIMÁNYI, 2016).

Pelo exposto até o presente momento, os mercados não podem ser entendidos como fenômeno natural e apesar de importante para sociedade contemporânea não significa que outras formas de organização social devam estar subordinadas a ele. A existência de pautas de contestação revela diferentes interesses e controvérsias dos atores que compõem um agenciamento de mercado remetendo ao que Callon et al. (2002) chamaram de fóruns híbridos. No que tange especificamente à disciplina de marketing, abre-se a possibilidade de resgatar debates que foram deslocados para margem em decorrência da consolidação da escola de pensamento gerencial (BLANCHET; DEPEYRE, 2015). Influenciadas por essas novas dimensões, pesquisas recentes associadas aos estudos construtivistas de mercado passaram a enfatizar fóruns de negociação compostos por atores econômicos, dos governos e da sociedade civil organizada reconhecendo-os como importantes sítios de pesquisa (D’ANTONE; SPENCER, 2014; AZIMONT; ARAUJO, 2014; ONYAS; RYAN, 2014). 
Ainda assim, Beuza e Ferraro (2018) se mostram céticos alegando que estudos sobre performatividade geralmente tendem a ignorar a dimensão política dos mercados e que o conceito de agenciamento sociotécnico, mais obscurece do que explica o fenômeno em questão. Como forma de superar tal desafio, propõem um diálogo entre a teoria ator-rede e a teoria institucional, ou de forma mais específica, entre performatividade, translação e artefatos materiais e a forma com que as instituições regulam e organizam práticas sociais por meio de normas para explicar a forma com que as dinâmicas micropolíticas provocam mudanças em determinados mercados.

A sugestão de Beuza e Ferraro (2018) em aproximar teoria institucional dos estudos sobre formação de mercado é desenvolvida na seção a seguir. Contudo, foco recairá sobre a contribuição de uma vertente específica: a perspectiva das lógicas institucionais (FRIEDLAND; ALFORD, 1991; THORNTON; OCASIO; LOUNSBURY, 2015).

\section{A PERSPECTIVA DAS LÓGICAS INSTITUCIONAIS}

Para Friedland e Alford (1991), compreender mercados a partir da teoria da escolha racional, um dos pressupostos da escola neoclássica de economia, implicaria em negligenciar suas dimensões simbólicas e culturais. Mercado, portanto, mais do que um mecanismo de alocação de recursos, encerra também um sistema cultural específico, que quando institucionalizado, é capaz de influenciar a forma com que atores geram, percebem e mensuram o valor das trocas. Dito de outra forma, mercado repercute o entendimento mais amplo proposto inicialmente pelos autores de que a sociedade é constituída por múltiplas lógicas institucionais. À medida que uma determinada prática decorrente de uma lógica seja institucionalizada, assume caráter normativo, e, portanto, fonte de legitimidade (FRIEDLAND; ALFORD, 1991; ROSSONI, 2016).

De certa forma, a perspectiva das lógicas institucionais apresenta uma alternativa em meio às controvérsias que circundam a vertente neoinstitucional (MEYER; ROWAN, 1977), sobre seu caráter conservador, determinista e apolítico que acabaria por projetar sombras sobre a capacidade de agência dos indivíduos (CARVALHO; VIEIRA; GOULART, 2005; MACHADO-DA-SILVA; FONSECA; CRUBELLATE, 2005; HUDSON et al., 2015; YU, 2015). Segundo Thornton, Ocasio e Lounsbury (2015) o que assegura a distinção da proposta de Friedland e Alford (1991) é a proposição justamente de uma visão não funcionalista e não determinística da sociedade, composta por ordens institucionais que juntas constituem um sistema institucional inter-relacionado. Isso significa que família, religião, Estado, ordens profissionais e mercado carregam significados simbólicos e práticas materiais, isto é, conteúdo institucional que influencia a organização da vida social. Se um dado indivíduo ou organização atuar em um campo organizacional 
influenciado mais por valores e crenças de mercado do que pelos valores e crenças de determinadas categorias profissionais, por exemplo, isso implicará na forma com que o sentido dado a esta realidade será produzido (THORNTON; OCASIO; LOUNSBURY, 2015). Portanto, as lógicas institucionais podem ser definidas como

"...as the socially constructed, historical pattern of material practices, assumptions, values, beliefs, and rules by which individuals produce and reproduce their material subsistence, organize time and space, and provide meaning to their social reality" (THORNTON; OCASIO, 1999, p. 804).

É importante ressaltar que embora as lógicas institucionais exerçam influência sobre indivíduos e organizações, isso não significa que esses atores não possuem espaço para agir. Como a sociedade e, por conseguinte, mercado, é composta por diferentes lógicas institucionais com correspondentes práticas materiais e simbólicas, atores sociais podem desenvolver mecanismos para conformar ou desafiar padrões estabelecidos. Desta forma, indivíduos podem manipular ou reinterpretar símbolos e práticas se apropriando de lógicas institucionais existentes ou preparando o terreno para o surgimento de novas (FRIEDLAND; ALFORD, 1991).

A natureza recursiva e relacional entre as instituições e as práticas materiais e ordens simbólicas, apontam para novos avanços teóricos no âmbito da análise institucional superando as limitações das abordagens funcionalistas que mantinham foco sobre o ordenamento social e manutenção do status quo. Segundo a perspectiva das lógicas institucionais, indivíduo e organização estão imersos em um ambiente produzido pela combinação de ordens institucionais, estando suas práticas e símbolos em constante processo de reinterpretação, exploração e mudança de acordo com interesses socialmente construídos para estabelecer uma relação de conformidade ou de conflito (THORNTON; OCASIO; LOUNSBURY, 2015). O foco sobre os efeitos das pressões isomórficas nos campos organizacionais e na sociedade (DIMAGGIO; POWELL, 2005) cede lugar aos efeitos produzidos por diferentes lógicas institucionais e a forma com que indivíduos e organizações, nos mais variados contextos, agem para preservá-las ou modificá-las (THORNTON; OCASIO, 2008; THORNTON; OCASIO; LOUNSBURY, 2012).

Para compreender como as instituições, a partir de suas lógicas de ação, influenciam e são influenciadas pelo comportamento de indivíduos e organizações em condições de estabilidade e mudança, Thornton e Ocasio (2008) destacam os seguintes pressupostos: a) o enraizamento da agência, que informa que os interesses, valores, identidades dos atores sociais estão inseridos nas lógicas institucionais prevalecentes; b) a sociedade como sistema inter-institucional, onde qualquer contexto é potencialmente influenciado por lógicas conflitantes de diferentes segmentos sociais; c) a natureza material e cultural das 
organizações, em que as instituições se desenvolvem ou mudam em decorrência do resultado da relação entre as práticas materiais e culturais (com destaque para os componentes simbólicos e normativos); d) instituições produzem efeitos em diferentes niveis de análise (indivíduo, organização e sociedade) em contextos diversos (por exemplo: mercado, indústria, comunidades); e e) contingência histórica, que recomenda a observação do conteúdo, significado e das mudanças institucionais considerando os efeitos econômicos, estruturais e normativos sobre indivíduos e organizações em determinado enquadramento espaço-temporal.

Estudos empíricos já exploraram a coexistência de múltiplas lógicas institucionais (REAY; HININGS; 2009; VENKATARAMAN et al., 2016) bem como a emergência de uma lógica dominante (NIGAM; OCASIO, 2010; CRUZ, 2014). Nigam e Ocasio (2010) investigaram a emergência e mudança na lógica institucional de um campo organizacional específico: o de hospitais. Os autores que combinaram a perspectiva de lógicas institucionais com sensemaking (WEICK, 1995) apontam que a lógica do campo decorre do processo de criação de sentido de seus integrantes inseridos em um contexto específico para lidar com eventos ambientais inesperados. Tal mecanismo pode produzir novas práticas materiais afetando a coexistência das lógicas institucionais já existentes. Cruz (2014) também identificou a transformação da lógica institucional do campo vitinícola gaúcho, antes marcado pela lógica tradicionalista, para uma lógica expansionista, observando diferentes períodos históricos que marcaram este setor.

Já Reay e Hinings (2009) investigaram os efeitos provocados pela existência de duas lógicas institucionais conflitantes no campo da saúde: uma mais recente baseada em negócios introduzida pelo governo em uma série de reformas administrativas e outra, a que já existia, baseada na categoria profissional dos médicos. Cada lógica estava associada a um conjunto de princípios organizativos e abrangia comportamentos de diferentes atores do campo. Segundo os autores nenhuma lógica poderia ser considerada dominante. Ambas coexistiam através de mecanismos próprios desenvolvidos pelas organizações do campo para acomodar a tensão existente entre essas duas lógicas. Ainda no que tange à existência de múltiplas lógicas, Venkataraman et al. (2016) mostraram como uma organização nãogovernamental usa estrategicamente duas lógicas institucionais distintas, de mercado e comunitária, para implementar seu intento de desenvolvimento local.

A questão que se apresenta agora é: de que forma a perspectiva de lógicas institucionais pode subsidiar avanços teóricos dos estudos construtivistas de mercado em marketing? Pode-se dizer que ambas compartilham a ideia de que a atividade econômica está incrustada no tecido social, como já sugeriram Fligstein (2001) e Callon (1998). Portanto, tal aproximação se daria no âmbito da sociologia econômica, entre as vertentes institucionalista e a da perfomatividade. 
Como já foi mencionada, a suposta neutralidade atribuída à teoria ator-rede, uma das bases teóricas dos estudos sobre formação de mercado, poderia erguer impedimentos no que diz respeito à apreensão da dimensão política dos actants que constituem mercado. Uma das formas de investigação possivel reside em observar as práticas de mercado, no nível micro, em consonância com o agenciamento sociotécnico de mercado, que corresponderia ao nível macro. Contudo, se assumido o entendimento de que o conceito de agenciamento encerra alguma sorte de dificuldades para apreensão dessa dimensão, conforme sugerido por Beuza e Ferraro (2018), a aproximação da perspectiva das lógicas institucionais pode fornecer outras vias de análise possível (MODELL et al., 2017).

Aaproximação entreabordagensinstitucionais, na qual se destaca a vertente das lógicas institucionais, e a teoria ator-rede, importante recurso para os estudos sobre formação de mercado, já foi defendida sob a argumentação de geração de benefícios mútuos. Czarniawska (2004) apresenta, por exemplo, o conceito de redes de ação como produto da combinação da nova teoria institucional com a sociologia da translação (outra denominação para a teoria ator-rede que emergiu na década de 1980 (CALLON, 1984)). A ênfase sobre as dinâmicas processuais observadas nos níveis micro, típico das abordagens que privilegiam as práticas, como é o caso da teoria ator-rede (GHERARDI, 2016), poderia contribuir para o tratamento estruturalista geralmente associado às abordagens institucionais (LOUNSBURY, 2008; TRYGGESTAD; GEORG, 2011). Ao mesmo tempo, o foco em descrever a prática de actants pode obscurecer elementos estruturais que concorrem para a estabilização de uma dada realidade, ainda que de forma temporária. Em outras palavras, mecanismos políticos, culturais, simbólicos e de poder presentes em abordagens institucionais (FLIGSTEIN, 2001) tenderiam a ser dissolvidos no emaranhado das descrições das práticas e no mapeamento das movimentações dos actants em um dado mercado quando o que poderia ser questionado era de que forma as lógicas institucionais estariam materializadas nas práticas de atores humanos e não humanos (MODELL et al., 2017).

Embora a aproximação entre a vertente das lógicas institucionais e os estudos de formação de mercado aponte para avenidas de investigação promissoras para essas duas tradições de pesquisa, tal esforço deve reconhecer e negociar as tensões ontológicas e epistemológicas entre os dois paradigmas (ver quadro 1). Neste sentido, as próprias práticas de pesquisa conduzidas sob essas tensões demandariam do pesquisador uma postura reflexiva (CUNLIFFE, 2004). À guisa de exemplo, não faz sentido para teoria ator-rede discutir niveis de análise uma vez que a sua ontologia plana está voltada para forma com que o real é produzido a partir do fluxo das práticas dos elementos heterogêneos que constituem as redes (SEIDL; WHITTINGTON, 2014). Por outro lado, a perspectiva das lógicas institucionais tende a adotar critério multinivel de análise estabelecido a priori (níveis macro, meso e micro) (THORNTON; OCASIO, 2008). 
Quadro 1. Comparação entre os pressupostos ontológicos e epistemológicos da teoria institucional e da teoria ator-rede.

\begin{tabular}{|c|c|c|}
\hline & Teoria Institucional & Teoria Ator-Rede \\
\hline \multicolumn{3}{|l|}{ Fundamentos Ontológicos } \\
\hline Concepção da realidade & $\begin{array}{l}\text { O real é socialmente construído instituindo, } \\
\text { em determinado período de tempo, uma } \\
\text { dimensão realista a partir da objetificação } \\
\text { das estruturas sociais. }\end{array}$ & $\begin{array}{l}\text { O real emerge de forma relacional e } \\
\text { construído em qualquer período de tempo. } \\
\text { O ator só existe à medida que estabelece/ } \\
\text { constitui relacionamento com outros } \\
\text { atores em um mesmo nível de análise. }\end{array}$ \\
\hline Concepção das estruturas sociais & $\begin{array}{l}\text { Estruturas existem como entidades reais } \\
\text { socialmente construídas, porém, em } \\
\text { termos ontológicos, à parte da agência } \\
\text { humana. }\end{array}$ & $\begin{array}{l}\text { Estruturas não são perenes, mas entidades } \\
\text { pré-existentes que condicionam a agência. } \\
\text { Elas podem emergir e se estabilizar } \\
\text { temporariamente como parte de um } \\
\text { processo de translação. }\end{array}$ \\
\hline Concepção de agência & $\begin{array}{l}\text { Agência humana está institucionalmente } \\
\text { enraizada e condicionada por estruturas } \\
\text { sociais historicamente constituídas. }\end{array}$ & $\begin{array}{l}\text { Entidades humanas e não-humanas } \\
\text { (actants) interagem de forma contínua e } \\
\text { ambas possuem capacidade para exercer } \\
\text { agência. }\end{array}$ \\
\hline $\begin{array}{l}\text { Concepção de mudança e } \\
\text { estabilidade }\end{array}$ & $\begin{array}{l}\text { Mudança possui natureza episódica, } \\
\text { excepcional, e está sempre associada às } \\
\text { instituições. }\end{array}$ & $\begin{array}{l}\text { Mudança possui natureza ambígua e } \\
\text { está inter-relacionada às práticas de } \\
\text { transformação dos atores em rede. A } \\
\text { estabilidade é uma condição frágil e } \\
\text { temporária. }\end{array}$ \\
\hline \multicolumn{3}{|l|}{ Fundamentos Epistemológicos } \\
\hline $\begin{array}{l}\text { Posição } \\
\text { direcionadora }\end{array}$ & $\begin{array}{l}\text { Empírica e indutiva, admitindo espaço } \\
\text { também para a dedução. }\end{array}$ & $\begin{array}{l}\text { Fortemente empírica, buscando descrições } \\
\text { únicas. Dedução e indução não possuem } \\
\text { papel significativo. }\end{array}$ \\
\hline Papel da teoria & $\begin{array}{l}\text { Visão da ciência normal buscando melhor } \\
\text { refinamento e maior alcance. }\end{array}$ & $\begin{array}{l}\text { Teoria não possui, em si, espaço relevante } \\
\text { na teoria ator-rede tornando a análise } \\
\text { indeterminada. }\end{array}$ \\
\hline $\begin{array}{l}\text { Pressupostos sobre unidades de } \\
\text { análise }\end{array}$ & $\begin{array}{l}\text { Definidos a priori, são relativamente fixos e } \\
\text { claramente demarcados. }\end{array}$ & $\begin{array}{l}\text { Deliberadamente instáveis no processo de } \\
\text { constituição das redes. }\end{array}$ \\
\hline
\end{tabular}

\section{Fonte: Adaptado de Modell et al. (2017).}

Dada a existência de múltiplas lógicas institucionais e observado que os interesses dos atores são socialmente construídos em um campo organizacional entendido como uma arena de disputa de política (MACHADO-DA-SILVA; FILHO; ROSSONI, 2010), tem-se nessa perspectiva uma possibilidade mais direta para acessar as regras e recursos que estão em jogo em relação ao conceito de agenciamento sociotécnico (ÇALISKAN; CALLON, 2010). 
No que tange à dimensão micro, as duas tradições teóricas manifestam uma preocupação de ordem pragmática expressa na máxima de "seguir os atores" na teoria ator-rede (LATOUR, 2012) e no conjunto de significados simbólicos e práticas materiais dos indivíduos que sugere a busca por conhecer sobre "o que as pessoas fazem e por que fazem o que fazem" (REAY; JONES, 2016). Portanto, no nível micro, se assegurada a opção pelas práticas de mercado, abre-se a possibilidade de que pelo menos duas dimensões sejam enriquecidas pela concepção das lógicas institucionais: as práticas normativas e a representacionais. De fato, Kjelberg e Helgesson (2006; 2007a) pouco discorrem sobre como mercado ganha novos contornos a partir da atuação política de seus atores. É importante lembrar que essa prática específica está intimamente ligada às demais pelo conceito de translação e entender a maneira como é performada por atores humanos e não-humanos resultaria em importantes avanços teóricos e analíticos para os estudos construtivistas de mercado.

A seção a seguir apresenta um quadro analítico com bases nas discussões até aqui conduzidas tomando como base uma organização específica que integra o sistema normativo e fiscalizador do mercado brasileiro de alimentos orgânicos: as Comissões da Produção Orgânica (CPOrg).

\section{PROPOSIÇÃO DE UM QUADRO ANALÍTICO PARA INVESTIGAÇÃO DAS COMISSÕES DA PRODUÇÃO ORGÂNICA}

O mercado brasileiro de produtos orgânicos é um mercado estruturado pela lei federal 10.831 publicada em 2003 (BRASIL, 2003) que posteriormente foi regulamentado pelo decreto 6.323 publicado em 2007 (BRASIL, 2007). De forma geral, a lei versa de maneira genérica sobre o sistema de produção orgânico e mecanismos de avaliação, porém apresenta de forma específica uma definição sobre produto orgânico no Artigo 2: "Considera-se produto da agricultura orgânica ou produto orgânico, seja ele in natura ou processado, aquele obtido em sistema orgânico de produção agropecuário ou oriundo de processo extrativista sustentável e não prejudicial ao ecossistema local" (BRASIL, 2003). Dentre os motivos de criação da lei, ganhou destaque à época, a necessidade de reduzir a assimetria de informações que posicionava o consumidor em uma condição de vulnerabilidade frente à oferta de produtos orgânicos (MEDAETS; FONSECA, 2005). A solução passaria, portanto, pela criação de um sistema nacional de governança e de fiscalização dos mecanismos de garantia da qualidade apresentados com a lei.

O decreto 6.323 (BRASIL, 2007) regulamentou os mecanismos de controle para a garantia da qualidade orgânica composto pelos Sistemas Participativos de Garantia da Qualidade e pela certificação por auditoria. Quando auditado tanto pela modalidade de Sistemas Participativos quanto pela auditoria e comprovar estar em conformidade com os requisitos legais, o produtor de produtos orgânicos será 
identificado com um selo válido em todo território nacional que indicará a modalidade de avaliação a qual foi submetido. Há uma terceira possibilidade comercializar produtos orgânicos que torna o selo prescindivel: a venda direta aos consumidores por agricultores familiares. Portanto, a comercialização de produtos orgânicos só é permitida quando o produtor atende, obrigatoriamente, aos requisitos de pelo menos uma das modalidades previstas em lei e regulamentada pelo decreto correspondente.

É importante frisar que tanto a modalidade da venda direta por agricultores familiares quanto a modalidade dos Sistemas Participativos foram contempladas pela lei 10.831(BRASIL, 2003) em virtude de pressões exercidas por movimentos sociais. Inicialmente, a única opção prevista em lei era a da certificação por auditoria (NIEDERLE; ALMEIDA, 2013). A lei e seu respectivo decreto representam, portanto, a produção de mecanismos que visam conciliar interesses de diversos atores sociais abrangendo desde grandes empresas até pequenas produções familiares (SAMBUICHI et al., 2017). Trata-se de um quadro composto por legislação, órgãos de fiscalização, organismos de certificação, produtores de diferentes portes, movimentos sociais, consumidores entre outros (SANTOS; HIGGINS, 2016). Reconhecer a pluralidade de atores (humanos e não humanos) envolvidos ao longo do processo de desenvolvimento do marco legal que estabelece os contornos do mercado de alimentos orgânicos não só atende aos pressupostos dos estudos construtivistas de mercado (D'ANTONE; SPENCER, 2014; ONYAS; RYAN, 2014) como abre espaço para investigar como coexistem as diferentes lógicas institucionais mobilizadas por cada um desses atores para tornar legítimas (FRIEDLAND; ALFORD, 1991; THORNTON; OCASIO; LOUNSBURY, 2015) suas práticas de mercado (KJELLBERG; HELGESSON, 2006; 2007a).

No que tange ao sistema de governança, a lei (BRASIL, 2003) também institui o Sistema Brasileiro de Avaliação da Conformidade Orgânica composto por diversas organizações e que cuja atuação ocorre sob os auspícios do Ministério da Agricultura, Pecuária e Abastecimento (MAPA). Um desses mecanismos ganha materialidade com a inclusão das Comissões da Produção Orgânica nas unidades federativas (CPOrg-UF) no decreto 6.323 (BRASIL, 2007). Vale ressaltar que essas comissões já existiam desde 2004, quando da criação pelo MAPA do Programa de Desenvolvimento da Agricultura Orgânica (PRO-ORGANICO) (BRASIL, 2004) cujos efeitos foram consolidados em 2008 pela instrução normativa nº 54 (BRASIL, 2008).

Atualmente o funcionamento das comissões é orientado pela instrução normativa n 13 publicada em 2015 (BRASIL, 2015) que em seu artigo 17 apresenta a suas atribuições dentre as quais destacamse: emitir parecer sobre regulamentos técnicos de produção orgânica em âmbito nacional e internacional; assessorar o Sistema Brasileiro de Conformidade Orgânica incluindo processo de acreditação de certificadoras bem como acompanhamento das Organizações de Controle Social (referente à modalidade que permite a venda direta); articular e fomentar fóruns que deem visibilidade aos movimentos sociais 
vinculados à temática da agricultura orgânica; e colaborar com a divulgação, expansão e fomento da produção orgânica nas unidades federativas.

As atribuições desta instância de governo composta, de forma paritária, por representantes do setor público e da sociedade civil (BRASIL, 2015) não somente revelam sua importância na elaboração e monitoramento de políticas públicas voltadas à agricultura orgânica, mas também a existência de práticas normativas e representacionais com implicações sobre as práticas de troca (econômicas) uma vez que todas as práticas, com especial destaque para as de mercado, estabelecem entre si, cadeias de translação (KJELLBERG; HELGESSON, 2006). Dito de outra forma, deliberações e discussões sobre normas legais de produção e comercialização de produtos orgânicos, no âmbito destas comissões, possuem repercussão sobre práticas de troca estabelecidas em feiras, supermercados, restaurantes e vendas governamentais.

Vale destacar que a atuação do movimento agroecológico, em parte, exerceu forte influência sobre o desenvolvimento do marco legal (MOURA, 2017). Uma breve análise sobre o decreto n 6.323 publicado em 2007 permite a verificação de comissões como a CNAPO (Comissão Nacional de Agroecologia e Produção Orgânica) como fórum público e privado cujas discussões podem nortear o rumo das políticas públicas do setor. Integravam essa comissão, representantes do movimento agroecológico.

Assumindo a perspectiva de lógicas institucionais (THORNTON; OCASIO; LOUNSBURY, 2015) é possível observar que a constituição do mercado brasileiro de alimentos orgânicos foi (e ainda é) pautada por disputas econômicas, ideológicas e culturais (NIEDERLE, 2014). Discussões sobre se o produto orgânico é uma mercadoria destinada a um nicho específico de consumidores ou se é um alimento saudável ao alcance da população, reverbera até que ponto esta nova forma de produção de alimentos se distingue da produção convencional e sua correspondente lógica de atuação (NIEDERLE, 2016). Essa controvérsia também ajuda a defender a preferência pela perspectiva das lógicas institucionais a agenciamentos sócio-técnicos (ÇALISKAN; CALLON, 2010) para investigar as práticas que formam o mercado de produtos orgânicos no Brasil.

Pelo exposto, afirma-se que pelo menos duas lógicas institucionais (THORNTON; OCASIO; LOUNSBURY, 2015) podem ser identificadas no mercado de produtos orgânicos: uma baseada nos preceitos da agroecologia, com um enfoque mais comunitário, e outra baseada em negócios, com enfoque mais empresarial (GRAEFF, 2011; SANTOS; HIGGINS, 2016). A agroecologia não versa somente sobre as regras de manuseio e produção de produtos orgânicos como insere discussões sobre o consumo democrático de alimentos livres de agrotóxicos e justiça social (MOURA, 2017). Já a lógica empresarial, entende produto orgânico como um produto alimentício de elevado valor agregado em relação aos que são convencionalmente produzidos, onde a relação entre produção e consumo pode ser retratada conforme os preceitos da economia neoclássica (SOUZA, 2000; GRAZIANO et al., 2011). 
Como as CPOrg-UF devem, por força de norma (BRASIL, 2007), possuir representantes dos setores públicos e privados, há a expectativa de que nesses fóruns sejam identificadas múltiplas lógicas institucionais além das duas já mencionadas e consideradas relevantes para a condução de pesquisas neste campo. Estas organizações, portanto, parecem ser locais propícios para investigação proposta neste ensaio. Toma-se, por exemplo, a composição da CPOrg do Rio de Janeiro, apresentada no quadro 2.

Se observada a composição do setor privado, as entidades da sociedade civil, é possivel perceber a presença de organizações que estão envolvidas diretamente em atividades comerciais, como a Agrosuisse (no ramo de consultoria), o Clube Orgânico e o restaurante Ser Orgânico (ambos no ramo de alimentação). Ainda integram a composição uma entidade de classe, a Sociedade Nacional da Agricultura (SNA), organizações não governamentais, como a ASPTA, associações de produtores, como a ABIO, e uma entidade privada de serviço social, o Sebrae. Já a composição governamental, envolve a participação de empresas públicas de pesquisa, como o Embrapa, universidades, secretarias de estado e da prefeitura da cidade do Rio de Janeiro entre outros. Quais seriam os interesses dessas organizações em participar da CPOrg-RJ? É importante lembrar que, como já fora mencionado, as CPOrg-UF podem influenciar os rumos da formação da política nacional de produção orgânica, com implicação para a formação deste mercado. Isso não deve necessariamente causar surpresa, pois o mercado de produtos orgânicos é um mercado regulado e em regulação. Um ponto em comum tanto entre as entidades governamentais quanto as da sociedade civil são as práticas normativas e representacionais, com implicações sobre as práticas de troca, e forma como poderiam explicar e serem explicadas pelas duas lógicas identificadas: a agroecológica e a empresarial. Desta forma, apresenta-se a seguinte proposição:

Proposição 1: as práticas normativas e representacionais dos atores que compõem as CPOrgUF mantêm uma relação recursiva e sociomaterialmente construída com as lógicas institucionais empresarial e agroecológica. 
Quadro 2. Membros da CPOrg-RJ

\begin{tabular}{|c|c|}
\hline Entidades Governamentais & Entidades da sociedade \\
\hline $\begin{array}{l}\text { Superintendência Federal de Agricultura no Estado do } \\
\text { Rio de Janeiro - SFA/RJ }\end{array}$ & Serviços Técnicos Agropecuários Ltda. - AGROSUISSE \\
\hline Embrapa - Agrobiologia & $\begin{array}{l}\text { Engenharia, Tecnologia e Desenvolvimento de Soluções } \\
\text { Limpas - AMBIENTE BRASIL }\end{array}$ \\
\hline $\begin{array}{l}\text { Universidade Federal do Rio de Janeiro (UFRJ) e } \\
\text { Universidade Federal Rural do Rio de Janeiro (UFRRJ) }\end{array}$ & Sociedade Nacional de Agricultura - SNA \\
\hline $\begin{array}{l}\text { Empresa de Pesquisa Agropecuária do Rio de Janeiro } \\
\text { - Pesagro-Rio }\end{array}$ & $\begin{array}{l}\text { Associação de Agricultores Biológicos do Estado do Rio } \\
\text { de Janeiro - ABIO }\end{array}$ \\
\hline $\begin{array}{l}\text { Instituto Federal do Rio de Janeiro - IFRJ / Campus Nilo } \\
\text { Peçanha e Pinheiral }\end{array}$ & $\begin{array}{l}\text { Associação dos Criadores de Abelhas do Médio Paraíba, } \\
\text { Centro e Baixada Fluminense - ACAMPAR }\end{array}$ \\
\hline $\begin{array}{l}\text { Secretaria de Desenvolvimento Econômico Solidário - } \\
\text { SEDES/PMRJ }\end{array}$ & $\begin{array}{l}\text { Serviço de Apoio às Micro e Pequenas Empresas do } \\
\text { Estado do Rio de Janeiro - SEBRAE/RJ }\end{array}$ \\
\hline $\begin{array}{l}\text { Empresa de Assistência Técnica e Extensão Rural do } \\
\text { Estado do Rio de Janeiro - EMATER-RIO }\end{array}$ & Associação dos Produtores Orgânicos do Vale do Café \\
\hline Instituto Estadual do Meio Ambiente - INEA & Instituto Maniva \\
\hline Instituto Nacional de Tecnologia - INT & $\begin{array}{l}\text { Assembleia Permanente em Defesa do Meio Ambiente } \\
\text { - APEDEMA }\end{array}$ \\
\hline EMBRAPA - Agroindústria de alimentos & $\begin{array}{l}\text { Associação dos Engenheiros Agrônomos do Estado do } \\
\text { Rio de Janeiro - AEARJ }\end{array}$ \\
\hline Secretaria de Meio Ambiente - SMAC/PMRJ & Clube Orgânico \\
\hline Companhia Nacional de Abastecimento - CONAB & Restaurante Ser Orgânico \\
\hline $\begin{array}{l}\text { Secretaria de Estado de Agricultura e Pecuária - } \\
\text { SEAPEC }\end{array}$ & $\begin{array}{l}\text { Assessoria e Serviços a Projetos em Agricultura } \\
\text { Alternativa - ASPTA }\end{array}$ \\
\hline
\end{tabular}

Fonte: Ministério da Agricultura Pecuária e Abastecimento. Disponivel em: http://www.agricultura.gov.br/assuntos/ sustentabilidade/organicos/arquivos-organicos/cporg-rj.pdf/view

Como as práticas normativas e representacionais estão associadas às práticas de troca por cadeias de translação formadas por atores humanos e não humanos, diferentes versões sobre o mercado de produtos orgânicos poderiam ser performadas. Tal performatividade pode ser, em parte, reflexo do conteúdo institucional das lógicas materializadas nos comportamentos e símbolos que expressam interesses políticos que podem ser observados nas práticas dos actants. Sendo assim, apresenta-se a segunda proposição: 


\section{Proposição 2: diferentes versões de mercado podem ser produzidas pelos actants a partir da} forma com que suas práticas mobilizam o conteúdo das lógicas institucionais para atender a agendas específicas de interesse.

A figura 1 decorre de um esforço para representar graficamente a proposta analítica até aqui desenvolvida. Dada a opção pela perspectiva das lógicas institucionais frente ao conceito de agenciamento sociotécnico, entende-se que no nivel macro existem múltiplas lógicas institucionais que permeiam o mercado brasileiro de produtos orgânicos. Duas merecem destaque, pois já foram identificadas: a empresarial e a agroecológica. Assume-se, portanto, que essas duas lógicas são reproduzidas e articuladas pelos diversos atores que compõem as CPOrg-UF. Tal fenômeno seria observado no nível micro, privilegiando dentre as práticas de mercado, a prática normativa e a representacional, uma vez que nesse espaço não são realizadas práticas de troca embora as influenciem. Contudo, dada as cadeias de translação formadas entre as práticas de mercado seria possivel verificar de que forma elas coexistem ao longo de um determinado período de tempo considerando a pluralidade de interesses políticos, sociais, culturais e econômicos.

Figura 1. Representação grăfica da proposta analítica.

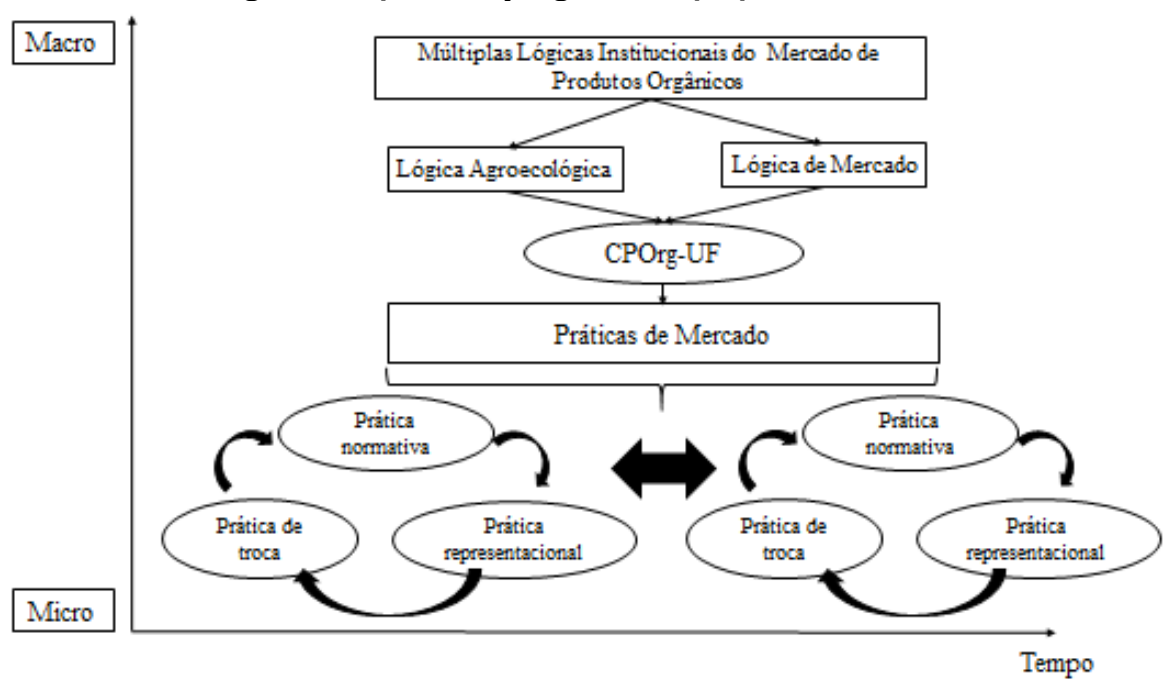

Fonte: Elaboração própria.

\section{CONSIDERAÇÕES FINAIS}

Este ensaio teve como objetivo investigar como a perspectiva de lógicas institucionais pode contribuir para a apreensão da dimensão política dos mercados no domínio dos estudos construtivistas de mercado, 
em especial, àqueles baseados no conceito de práticas de mercado. Trata-se de uma dimensão controversa entre os principais referenciais deste movimento e de nebuloso acesso em termos operacionais quando utilizado o conceito de agenciamento sociotécnico.

Argumenta-se que a perspectiva das lógicas institucionais pode contribuir para o avanço dos estudos construtivistas de mercado em marketing uma vez que reconhece a existência de diferentes ordens institucionais. A relação recursiva que estabelece com as práticas sociais de atores que mobilizam conteúdos simbólicos, crenças e valores não só ajuda a explicar a produção de múltiplas realidades de mercado como abre espaço para investigar como coexistem e são negociadas diferentes lógicas institucionais em operação. No caso específico deste ensaio, as práticas sociais são entendidas a partir do conceito de práticas de mercado (de troca, representacional e normativa).

Contextualizar a discussão no mercado brasileiro de alimentos orgânicos ajudou a ilustrar a proposta. Os contornos deste mercado foram estabelecidos com a criação do marco legal que, ao longo do seu desenvolvimento, contou com a participação de atores econômicos e sociais que possuíam agendas de interesse conflitantes, revelando uma dimensão política. 0 reconhecimento de outros atores que não somente os econômicos é um dos requisitos dos estudos construtivistas de mercado que refutam a reprodução da representação dominante deste fenômeno em marketing e possibilita investigar como suas práticas de mercado estão associadas a diferentes lógicas institucionais. Esta possibilidade se apresenta ainda mais viável quando observada a estrutura de governança produzida pelo marco legal, especificamente no que concerne às Comissões de Produção Orgânica das unidades federativas, as CPOrg-UF.

Compostas por atores governamentais e da sociedade civil, essas comissões desempenham importante papel em seus respectivos estados e para o governo federal quanto à fiscalização, à apreciação e elaboração de normas técnicas e ao fomento da produção orgânica. Observada a composição da CPOrg do estado do Rio de Janeiro e a construção o marco regulatório, supõe-se a existência de pelo menos duas lógicas institucionais: uma baseada nos preceitos da agroecologia, com um enfoque mais comunitário, e outra baseada em negócios, com enfoque mais empresarial. A materialização do conteúdo institucional de cada uma das lógicas ocorreria por meio das práticas de mercado, no caso específico da organização em questão, das práticas representacionais e normativas já que não abriga transações comerciais. Ainda assim, como as práticas de mercado estão vinculadas por cadeias de translação, as práticas de comerciais podem ser afetadas pelas práticas normativas e representacionais, por exemplo, na definição das exigências que cercam os espaços de comercialização como feiras e lojas varejistas.

Argumenta-se que as práticas representacionais que mantêm relação com a lógica agroecológica tendam a representar o mercado de produtos orgânicos de modo a influenciar as práticas normativas 
(e, portanto, formulação de políticas públicas e ações de fomento) e de troca de forma distinta daquelas associadas à lógica mais baseada em negócios, suscitando questionamentos que demandariam investigações empíricas: como essas duas lógicas coexistem nestas comissões? A coexistência é pacífica ou conflituosa? Qual a repercussão sobre as práticas de mercado? Como as práticas representacionais, que incluem e excluem os atores quem fazem parte desse mercado, reforçam ou desafiam cada uma das lógicas? Qual a importância dessas práticas junto às práticas normativas que concorrem para a formulação de políticas públicas? Quais são as implicações dessas práticas sobre a prática comerciais?

O conceito de práticas de mercado sustenta ser promissor ao nível micro de análise que, equipado com a perspectivas das lógicas institucionais, para análise ao nível macro, ajudaria a apreender e lançar luz sobre a dimensão política do mercado de produtos orgânicos a partir de investigações empíricas junto às Comissões de Produção Orgânica que devem existir em cada unidade da federação sob a responsabilidade do Ministério da Agricultura, Pecuária e Abastecimento. Esta possível agenda de pesquisa, baseada nas proposições do presente ensaio, contribuiria no âmbito dos estudos construtivistas de mercado para o recrudescimento de pesquisas que mostram preocupação com a dimensão social deste fenômeno (GEIGER; HARRISON; KJELLBERG; MALLARD, 2014), além de municiar a disciplina de marketing a lidar com questões associadas à sustentabilidade dado ceticismo existente nesta aproximação (DIÓGENES; SILVA, 2017) e seu impacto sobre práticas empresariais (SPALENZA; AMARAL, 2018) e sobre os consumidores (PACHECO et al., 2019).

Uma possivel limitação a essa abordagem, que foge ao escopo do presente ensaio, reside no ajuste de natureza ontológica e epistemológica entre as duas tradições teóricas utilizadas caso desperte algum tipo de desconforto entre pesquisadores preocupados com a questão da incomensurabilidade epistemológica. Ao mesmo tempo pode ensejar, em outros, discussões sobre condução de pesquisas sob perspectivas multiparadigmáticas e a importância da reflexividade nas práticas de pesquisa.

\section{REFERÊNCIAS}

ALCADIPANI, Rafael; HASSARD, John. Actor-network theory, organizations and critique: towards a politics of organizing. Organization, vol. 17, n² 4, 2010.

ALCADIPANI, Rafael; TURETA, Cesar. Teoria ator-rede e estudos críticos em administração: possibilidades de um diálogo. Cad. EBAPE.BR, vol. 7, n³ 3, 2009. 
ANDRADE, Jackeline Amantino de; VALADÃO, José de Arimatéia Dias. Análise da instrumentação da ação pública a partir da teoria do ator-rede: tecnologia social e a educação no campo em Rondônia. Revista de Administração Pública, vol. 51, nº 3, 2017.

ARAUJO, Luis. Markets, market-making and marketing. Marketing Theory, vol. 7, n³, 2007.

ARAUJO, Luis; FINCH, Jonh; KJELLBERG, Hans. Reconnecting marketing to markets: an introduction. In: ARAUJO, Luis; FINCH, Jonh; KJELLBERG, Hans (eds.). Reconnecting marketing to markets. Oxford: Oxford University Press, 2010.

ARAUJO, Luis; KJELLBERG, Hans. Shaping exchanges, performing markets: the study of market-ing practices. In: MACLARAN, Pauline; SAREN, Michael; STERN, Barbara; TADAJEWSKI, Mark. The SAGE Handbook of Marketing Theory. London: SAGE Publications Ltd., 2009.

ARAUJO, Luis; KJELLBERG, Hans; SPENCER, Rob. Market practices and forms: introduction to special issue. Marketing Theory, vol. 8, $n^{\circ} 1,2008$.

ARNDT, Johan. The political economy of marketing systems: reviving the institutional approach. Journal of Macromarketing, vol.1, $n^{\circ} 2,1981$.

ARNDT, Johan. Toward a concept of domesticated markets. Journal of Marketing, vol. 43, 1979.

BEUZA, Daniel; FERRARO, Fabrizio. Performative work: bridging performativity and institutional theory in the responsible investment field. Organization Studies, p.1-19, 2018.

BLANCHET, Vivien; DEPEYRE, Colette. Exploring the shaping of markets through controversies: methodological propositions for macromarketing studies. Journal of Macromarketing, vol. 36, n² 1, 2015.

BRASIL. Instrução Normativa $\mathbf{N}^{\circ} \mathbf{1 3}$, de $\mathbf{2 8}$ de maio de 2015. Estabelece a estrutura, a composição e as atribuições da subcomissão temática de produção orgânica (STPOrg), a estrutura, a composição e as atribuições das comissões da produção orgânica nas unidades da federação (CPOrg-UF), e as diretrizes para a elaboração dos respectivos regimentos internos. Diário Oficial, Brasília, p. 20, 29/05/2015.

BRASIL. Instrução Normativa N 54, de 22 de outubro de 2008. Regulamenta a estrutura, composição e atribuiç̧ões das Comissões da Produção Orgânica. Diário Oficial, Brasília, p.36-37, 23/10/2008.

BRASIL. Lei Nº 10.831, de 23 de dezembro de 2003. Dispõe sobre a agricultura orgânica e dá outras providências. Diário Oficial, Brasília, p.8, 24/12/2003. 
BRASIL. Lei № $\mathbf{6 . 3 2 3}$, de 27 de dezembro de 2007. Regulamenta a Lei n 10.831, de 23 de dezembro de 2003, que dispõe sobre agricultura orgânica, e dá outras providências. Diário Oficial, Brasília, p.2-8, 24/12/2007.

BRASIL. Portaria N 158, de 8 de julho de 2004. Determina que o Programa de Desenvolvimento da Agricultura Orgânica, PRO-ORGÂNICO, nos assuntos relativos a sua execução, seja assessorado pela Comissão Nacional da Produção Orgânica - CNPOrg e pelas Comissões da Produção Orgânica nas Unidades da Federação - CPOrg-UF. Diário Oficial, Brasilia, p. 5, 09/07/2004.

BUTLER, Judith. Performative agency. Journal of Cultural Economy, vol. 3, n² 2, 2010.

ÇALISKAN, Koray; CALLON, Michel. Economization, part 2: a research program for the study of markets. Economy and Society, vol. 39, vol. 1, 2010.

CALLON, Michel (ed.). The Laws of Markets. Oxford: Blackwell Publishers, 1998.

CALLON, Michel. Elaborating the notion of performativity. Le Libellio d'Aegis, vol. 5, n 1, 2009a.

CALLON, Michel. Introduction: the embeddedness of economic markets in economics. In: CALLON, Michel (ed.). The Laws of the Markets. Oxford: Blackwell Publishers, 1998a.

CALLON, Michel. Marketing as an art and science of market framing: commentary. In: ARAUJO, Luis; FINCH, John; KJELLBERG, Hans (eds.). Reconnecting marketing to markets. Oxford: Oxford University Press, 2010.

CALLON, Michel. Performativity, misfires and politics. Journal of Cultural Economy, vol. 3, n 2, 2010.

CALLON, Michel. Some elements of a sociology of translation: domestication of the scallops and the fishermen of St Brieuc Bay. The Sociological Review, vol. 32, n 1, 1984.

CALLON, Michel. What does it mean to say that economics is perfomative? In: MACKENZIE, Donald; MUNIESA, Fabian; SIU, Lucia (eds.). Do economists make markets? On the performativity of economics. Princeton: Princeton University Press, 2007.

CALLON, Michel. Why virtualism paves the way to political impotence: a reply to Daniel Millers's critique of "The laws of the market". Economic Sociology: European Eletronic Newsletter, vol. 6, n², 2005.

CALLON, Michel; MÉADEL, Cécile; RABEHARIOSA, Vololona. The economy of qualities. Economy and Society, vol. 31, $n^{\circ} 2,2002$. 
CAMILLIS, Patricia; ANTONELLO, Claudia. Da translação para o enactar: contribuições da Teoria Ator-Rede para a abordagem processual das organizações. Cad. EBAPE.BR, vol. 14, nº 1, 2016.

CARVALHO, Cristina; VIEIRA, Marcelo; GOULART, Sueli. A trajetória conservadora da teoria institucional. Revista de Administração Pública, vol. 39, n 4, 2005.

COCHOY, Franck; GIRAUDEAU, Martin; MCFALL, Liz. Performativity, economics and politics. Journal of Cultural Economy, vol. 3, n² 2, 2010.

COCHOY, Franck; TROMPETTE, Pascale; ARAUJO, Luis. From market agencements to market agencing: an introduction. Consumption Markets \& Culture, vol. 19, nº 1, p. 3-16, 2016.

COOREN, François. Textual agency: how texts do things in organizational setting. Organization, vol. 11, $n^{\circ} 3,2004$.

CRUZ, Guillermo. Lógica institucional e a mudança inovadora em campos institucionais: as transformações no campo vitivinícola gaúcho. In: VIII Encontro de Estudos Organizacionais da ANPAD - ENEO, 8., 2014, Gramado. Anais... Gramado, 2014.

CUNLIFFE, Ann. On becoming a critically reflexive practitioner. Journal of Management Education, vol. $28, n^{\circ} 4,2004$.

CZARNIAWSKA, Barbara. On time, space, and action nets. Organization, vol. 11, nº 6, 2004.

D'ANTONE, Simona; SPENCER, Robert. Concerns and marketization: the case of sustainable palm oil. In: GEIGER, Susi; HARRISON, Debbie; KJELLBERG, Hans; MALLARD, Alexandre. Concerned markets: economic ordering for multiple values. Cheltenham: Edward Elgar Publishing Limited, 2014.

DIMAGGIO, Paul; POWELL, Walter. A gaiola de ferro revisitada: isomorfismo institucional e racionalidade coletiva nos campos organizacionais. Revista de Administração de Empresas, vol. 45, n² 2, 2005.

DIÓGENES; Abílio; SILVA, MINELLE. O estudo do ceticismo nas publicações de marketing verde: uma revisão de publicações brasileiras. Revista Gestão e Desenvolvimento, vol. 14, n 1, 2017.

FINCH, John; GEIGER, Susi. Constructing and contesting markets through the market object. Industrial Marketing Management, vol. 40, $n^{\circ}$ 6, 2011.

FLIGSTEIN, Neil. Habilidade social e teoria dos campos. Revista de Administração de Empresas, vol. 47, $n^{\circ} 2,2007$. 
FLIGSTEIN, Neil. The architecture of markets. Princeton: Princeton University Press, 2001.

FLIGSTEIN, Neil; DAUTER, Luke. A sociologia dos mercados. Caderno CRH, vol. 25, n 66, 2012.

FRIEDLAND, Roger; ALFORD, Robert. Bringing society back in Symbols, practices and institutional contradictions. In: POWELL, Walter; DIMAGGIO, Paul (eds). The new institutionalism in organizational analysis. Chicago: Univesity of Chicago Press, 1991.

FUENTES, Christian; FUENTES, Maria. Making a market for alternatives: marketing devices and the qualification of vegan milk substitute. Journal of Marketing Management, vol. 33, n 7-8, 2017.

GEIGER, Susi.; HARRISON, Debbie.; KJELLBERG, Hans.; MALLARD, Alexandre. Concerned markets: economic ordering for multiple values. Cheltenham: Edward Elgar Publishing Limited, 2014.

GEIGER, Susi; FINCH, John. Promissories and pharmaceutical patents: agencing markets through public narratives. Consumption, Markets \& Culture, vol. 19, n²1, 2016.

GEIGER, Susi; KJELLBERG, Hans; SPENCER, Robert. Shaping exchanges, building markets. Consumption, Markets \& Culture, vol. 15, n², 2012.

GHERARDI, Silvia. To start practice theorizing anew: the contribution of the concepts of agencement and formativeness. Organization, vol. 23, n² 5, 2016.

GILSON, Lucy; GOLDBERG, Caren. Editor's comment: so, what is a conceptual paper? Group \& Organization Management, vol. 40, $n^{\circ}$ 2, 2015.

GRAEFF, Júlia. Sensemaking e sensegiving: a construção da lógica institucional do campo da agricultura familiar na região metropolitana de Curitiba/PR no período de 1990-2010. 2011. 155f. Tese (Doutorado em Administração). Universidade Federal do Paraná, Paraná.

GRANOVETTER, Mark. Economic action and social structure: the problem of embeddedness. American Journal of Sociology, vol. 91, n 3, 1985.

GRAZIANO, Graziela; CAMPANARIO, Milton; FILHO, Milton. Produtos orgânicos: as ferramentas para a sua sustentabilidade econômica. Revista de Gestão Social e Ambiental, vol. 5, n 3, 2011.

HAGBERG, Johan. Agencing practices: a historical exploration of shopping bags. Consumption Markets \& Culture, vol. 19, $n^{\circ} 1,2016$. 
HOPKINSON, Gillian. Making a market for male dairy calves: alternative and mainstream relationality. Journal of Marketing Management, vol. 33, n 7-8, 2017.

HUDSON, Bryant; OKHUYSEN, Gerardo; CREED, W. Power and institutions: stones in the road and some yellow bricks. Journal of Management Inquiry, vol. 24, n³ 3, 2015.

JAAKKOLA, Elina. Designing conceptual articles: four approaches. AMS Review, vol. 10, nº 1-2, 2020.

KJELLBERG, Hans; HELGESSON, Claes-Fredrik. Multiple versions of markets: multiplicity and performativity in the market practice. Industrial Marketing Management, vol. 35, n² 7, 2006.

KJELLBERG, Hans; HELGESSON, Claes-Fredrik. On the nature of markets and their practices. Marketing Theory, vol. 7, n² 2, 2007a.

KJELLBERG, Hans; HELGESSON, Claes-Fredrik. The mode of exchange and shaping of markets: distributor influence in the Swedish post-war food industry. Industrial Marketing Management, vol. 36, $n^{\circ} 7$, 2007b.

KJELLBERG, Hans; OLSON, David. Joint markets: how adjacent markets influence the formation of regulated markets. Marketing Theory, vol. 17, n²1, 2017.

LATOUR, Bruno. Ciência em ação: como seguir cientistas e engenheiros sociedade afora. São Paulo: Editora UNESP, 2000.

LATOUR, Bruno. On recalling ANT. In: LAW, John; HASSARD, John (eds). Actor Network Theory and After. Oxford: Blackwell Publishers, 1999.

LATOUR, Bruno. Reagregando o social. Salvador: Edufba, 2012.

LATOUR, Bruno. The powers of association. In: LAW, John (ed.). Power, action and belief: a new sociology of knowledge? London: Routledge \& Kegan Paul, 1986.

LAW, John; HASSARD, John (eds). Actor Network theory and After. Oxford: Blackwell Publishers, 1999.

LOUNSBURY, Michael. Institutional raionality and practice variation: new directions in the institutional analysis of practice. Accounting, Organizations and Society, vol. 33, n 4-5, 2008.

MACHADO-DA-SILVA, Clovis; FILHO, Edson; ROSSONI, Luciano. Campos organizacionais: seis diferentes leituras e a perspectiva de estruturação. Revista de Administração Contemporânea, edição especial, art. 5, p. 109-147, 2010. 
MACHADO-DA-SILVA, Clóvis; FONSECA, Valeria; CRUBELLATE, João. Estrutura, agência e interpretação: elementos para uma abordagem recursiva do processo de institucionalização. Revista de Administração Contemporânea, vol. 9, edição especial, 2005.

MASON, Katy; KJELLBERG, Hans; HAGBERG, Johan. Exploring the performativity of marketing: theories, practices and devices. Journal of Marketing Management, vol. 31, nº1-2, 2015.

MEDAETS, Jean; FONSECA, Maria. Produção orgânica: regulamentação nacional e internacional. Brasilia: Ministério do Desenvolvimento Agrário, NEAD, 2005.

MENEGHETTI, Francis. O que é um ensaio-teórico? Revista de Administração Contemporânea, vol. 15, $n^{\circ} 2,2011$.

MEYER, J.; ROWAN, B. Institutionalized organizations: formal structure as myth and ceremony. American Journal of Sociology, vol. 83, $n^{\circ} 2,1977$

MODELL, Sven; VINNARI, Eija; LUKKA, Kari. On the virtues and vices of combining theories: the case of institutional and actor-network-theory theories in accounting research. Accounting, Organizations and Society, vol. 60, 2017.

MOURA, Iracema. Antecedentes e aspectos fundantes da agroecologia e da produção orgânica na agenda das políticas públicas no Brasil. In: SAMBUICHI et al. (org). A política nacional de agroecologia e produção orgânica no Brasil: uma trajetória de luta pelo desenvolvimento rural sustentável. Brasília: Ipea, 2017.

NIEDERLE, Paulo. Mercados como arenas de luta por reconhecimento: disputas morais na construção dos dispositivos de qualificação dos alimentos. Política \& Sociedade, vol. 15, n 33, 2016.

NIEDERLE, Paulo. Os agricultores ecologistas nos mercados para alimentos orgânicos: contramovimentos e novos circuitos de comercio. Sustentabilidade em Debate, vol. 5, nº 3, 2014.

NIEDERLE, Paulo; ALMEIDA, Luciano. A nova arquitetura dos mercados para produtos orgânicos: o debate da convencionalização. In: NIEDERLE, Paulo; ALMEIDA, Luciano; VEZZANI, Fabiane (org.). Agroecologia: práticas, mercados e políticas para uma nova agricultura. Curitiba: Kairós, 2013.

NIGAM, Amit; OCASIO, William. Event attention, environmental sensemaking and change in institutional logics: an inductive analysis of the effects of public attention to Clinton's Health Care Reform initiative.

Organization Science, vol. 21, n 4, p. 823-841, 2010. 
NILSSON, Johan; HELGESSON, Claes-Fredrik. Epistemologies in the wild: local knowledge and the notion of performativity. Journal of Marketing Management, vol. 31, nº 1-2, 2015.

PACHECO, Paulo; SILVA, Hermes; SPERS, Eduardo; HAMZA, Kavita. As vertentes do consumo sustentável: um estudo comparativo entre consumidores com a formação ambiental e consumidores em geral.

Revista Gestão e Desenvolvimento, vol. 16, n 1, 2019.

PELLANDINI-SIMÁNYI, Léna. Non-marketizing agents in the study of markets: competing legacies of performativity and actor-network-theory in the marketization research program. Journal of Cultural Economy, vol. 9, nº 6, 2016

REAY, Trish; HININGS, C. Managing the rivalry of competing institutional logics. Organization Studies, vol. $30, n^{\circ} 6,2009$.

REAY, Trish; JONES, Candace. Qualitatively capturing institutional logics. Strategic Organization, vol. 14, $n^{\circ} 1,2016$.

REDMOND, William. Marketing systems and Market failure: a macromarketing appraisal. Journal of Macromarketing, vol. 38, $n^{\circ}$ 4, 2018.

ROSSONI, Luciano. O que é legitimidade organizacional? Revista Organização \& Sociedade, vol. 23, $\mathrm{n}^{\circ}$ 76, p. 110-129, 2016

RUIZ, Carlos. Theories of markets: insights from marketing and the sociology of markets. The Marketing Review, vol. 12, n 1, 2012.

SAMBUICHI, Regina et al. Introdução. In: SAMBUICHI et al. (org). A política nacional de agroecologia e produção orgânica no Brasil: uma trajetória de luta pelo desenvolvimento rural sustentável. Brasilia: Ipea, 2017.

SANTOS, Djalma; HIGGINS, Silvio. A construção de um regime de equidade no mercado brasileiro de produtos orgânicos. Política \& Sociedade, vol. 15, n³3, 2016.

SCHNEIBERG, M.; LOUNSBURY, M. Social movements and the dynamics of institutions and organizations. In: GREENWOOD, Royston.; OLIVER, Christine; LAWRENCE, Thomas; MEYER, Renate (eds). The Sage Handbook of Organizational Institutionalism. London: Sage, 2017.

SEIDL, David; WHITTINGTON, Richard. Enlarging the strategy-as-practice research agenda: towards taller and flatter ontologies. Organization Studies, vol. 35, n 10, 2014.

SHAW, Eric; JONES, D. A history of schools of marketing thought. Marketing Theory, vol. 5, n³, 2005. 
SMELSER, Neil; SWEDBERG, Richard. The handbook of economic sociology. Princeton: Princeton University Press, 2005.

SOUZA, Maria. Produtos orgânicos. In: ZYLBERSTAJN, Decio; NEVES, Marcos (eds). Economia e Gestão dos Negócios Agroalimentares. São Paulo: Pioneira, 2000.

SPALENZA, André; AMARAL, Mariana. Estratégia organizacional voltada para a lucratividade e sustentabilidade: um estudo de caso. Revista Gestão e Desenvolvimento, vol. 15, n 1, 2018.

SWEDBERG, 2004. Sociologia econômica: hoje e amanhã. Tempo Social, Revista de Sociologia da USP, vol. $12, n^{\circ} 2,2004$.

THORNTON, P.; OCASIO, W. Institutional logics. In: GREENWOOD, R.; OLIVER, C.; SAHLIN, K.; SUDDABY, R. (eds). The Sage Handbook of Organizational Institutionalism. London: Sage, 2008.

THORNTON, Patricia; OCASIO, William. Institutional logics and the contingency of power in organizations: executive succession in the higher education publishing industry, 1958-1990. American Journal of Sociology, vol. 105, n³, p. 801-843, 1999.

THORNTON, Patricia; OCASIO, Willian; LOUNSBURY, Michael. The institutional logics perspective: a new approach to culture, structure and process. Oxford: Oxford University Press, 2012.

TONELLI, Dany. Origens e afiliações epistemológicas da Teoria Ator-Rede: implicações para a análise organizacional. Cad. EBAPE.BR, vol. 14, n² 2, 2016.

TRYGGESTAD, Kjell; GEORG, Susse. How objects shape logics in construction. Culture and Organization, vol. 17, n³ 2011.

VAREY, Richard. The economics basis of marketing. In: BAKER, Michael; SAREN, Michael. Marketing Theory: A Student Text. London: SAGE Publications LTDA, 2010.

VENKATARAMAN, H.; VERMEULEN, P.; RAAIJMAKERS, A.; MAIR, J. Market meets community: institutional logics as strategic resources for development work. Organization Studies, vol. 37, n 6, 2016.

VENKATESH, Alladi; PEÑALOZA. From marketing to the market: a call for a paradigm shift. In: SETH, Jagdish; SISODIA, Rajendra (orgs). Does marketing need reform? Fresh perspectives on the future. New York: Routledge, 2006.

WEICK, Karl. Sensemaking in organizations. London: Sage, 1995.

YU, Kyoung-Hee. Institutional pluralism, organizations, and actors: a review. Sociology Compass, vol. 9, $n^{\circ} 6,2015$. 